and fishes. In the Colleges, there are laboratories at St. John's, Sidney Sussex, and Downing ; and we believe that Trinity College contemplates establishing one.

(3) INDUCEMENTS. - The degree of B.A. may be obtained in Natural Sciences. An examination in Honours was instituted in $185 \mathrm{I}$; in $186 \mathrm{I}$ the regulations were revised, and the successful candidates were declared entitled to a degree. Ninety-five students have passed this examination in the nine years since the alteration. A candidate for an ordinary degree may also select for the subject of his third or final examination one of the following subjects: Chemistry, Physics, Geology, Botany, Zoology. In the Colleges: Clare gives annually a scholarship, value 5ol.; Caius two, value not stated, one for Chemistry, the other for Anatomy; Christ's has lately oftered scholarships, from one to four in number, and from $30 l$. to $70 l$. in value, according to the merit of the candidates; St. Peter's gives annually one of the value of $60 l$; St. John's gives annually an exhibition of $50 \%$. for three years to students commencing residence; this College has also just instituted an annual examination in the Natural Sciences for its resident students, for proficiency in which prizes in books and pecuniary rewards will be given, as in the other College examinations; Trinity gives annually one foundation scholarship, tenable till the holder is of M.A. standing; Siciney Sussex, two scholarships annually, value 4ol., with opportunity of promotion, for Mathematics or Natural Science; Downing gives annually at least one scholarship, value 4ol. A fuller description of these will be found in No. 6 of this periodical, p. 169.

In looking through the lists of the Natural Sciences Tripos, fourteen persons will be found to have been elected fellows, but in most cases the candidate has been not without distinction in other branches of study. In several, however, proficiency in Natural Science was the declared cause of the election.

These statements are made upon the authority of the last volume of the Cambridge Calendar, supplemented in some instances by personal knowledge.

Thus much has been done: of what remains to do it is perhaps better that one, who is a resident and engaged to some extent in the work, should refrain from speaking. On this point only I may venture to express my conviction, that the coldness and even dislike with which the study of Natural Science was once regarded here is rapidly passing away, that the number of earnest students in the various branches is annually increasing, and that the University is fully alive to the wants of the age; so that, while she can never neglect or forget those old paths of Classics and Mathematics in which many of her sons have won an almost world-wide reputation, she will heartily welcome, and will regard with no less pride, all who are among the followers of sciences of a more recent date.

T. G. BONNEY

\section{THE MEASUREMENT OF GEOLOGICAL TIME} II.

WE have now to consider an entirely distinct set of facts which have an important bearing on the probable time elapsed since the last glacial epoch. Messrs. A. 'Tylor, Croll, and Geikie have shown that the amount of denudation now taking place is much greater than has generally been supposed. The quantity of water discharged by several rivers and the quantity of sediment carried down by those rivers have been measured with tolerable accuracy, and allowing for the difference of specific gravity between sediment and rock, it can be easily calculated, from the known area of each river basin, what average thickness las been removed from its whole surface in a year, since all the matter brought down by the river must evidently have come from some part of its basin. In this way it is found that the Mississippi has its basin lowered $\frac{1}{6000}$ of a foot per annum; the Ganges, $\frac{7}{2358}$; the Rhone, $\frac{1}{1528}$; the Hoang-Ho, $\frac{1}{1464}$; the Po, $\frac{7}{72}$.

But it is evident that this amount will be distributed very unequaily over different parts of the basin, according as the surface is flat or sloping, whether the slopes are of loose soil or of rock, whether the rock is solid or friable. The perfectly flat alluvial plains that form a considerable part of many river basins, will not only suffer no denudation, but will generally receive deposits of sediment during floods, and all such flat lands should therefore be deducted from the area of the river. Slightly undulating lands, especially if well covered with forest, will also suffer scarcely any denudation, as is well seen in the case of the Rio Negro branch of the Amazon and other black water rivers of South America, which hardly carry down any perceptible sediment even when in full flood. Again, wherever lakes occur, they receive all the sediment from the basin above them, which portion should therefore be treated by itself, since it contributes no sediment to the main river. If we look at a physical map of North America we see that a large extent of the Mississippi basin consists of alluvial flats and slightly undulating prairie, sufficiently explaining its small proportionate cienudation. Even the Rhone, which has a high rate of denudation, flows through a great extent of low lands and perfectly flat meadows, while the upper portion of its valley which produces most sediment is cut off by the Lake of Geneva. In order, therefore, to arrive at any fair estimate of the amount of denudation in the upland and mountainous portions of the Rhone valley (which is what we require for our purpose) we have considerably to reduce the area of its basin by taking away the flat lands in all its valleys, and considerably to increase the amount of sediment by adding all that is now poured into the Lake of Geneva. We shall probably not be far wrong in adding one third to its denuding powers on these grounds, which will lead us to the startling fact that the Rhone basin is being lowered at the rate of a foot in a thousand years; but even this is considerably less than in the case of the Po. Mr. Croll takes the Mississippi denudation of a foot in six thousand years as a measure for that of Europe ; but for reasons above stated I conceive this to be quite out of the question, and I maintain, that if we are to use his measure of denudation for any practical purpose, we must apply that of European rivers to European phenomena, that of Alpine rivers to Alpine phenomena, and must further make the necessary corrections for alluvial flats and intercepting lakes.

Mr. Croll and Sir Charles Lyell were at first both inclined to adopt the period of high excentricity which occurred from 750,000 to 950,000 years ago as that of the glacial epoch, but Mr. Croll, in consideration of the proofs of rapid denudation above given, now believes that the 
period beginning about 240,000 and ending about 80,000 years ago, is the more likely one. Even this, however, offers difficulties. Denudation in Wales and Scotiand must probably have gone on as rapidly as the average rate of the Rhone valley, especially during the period when the old glaciers were disappearing; and eighty thousand years will therefore imply eighty feet of average denudation over the whole surface of the country, if less in one part then correspondingly more in another; but how is this consistent with the preservation of ice-ground rock-surfaces and glacial furrows in so many situations, as well as numberless heaps of loose matter, the moraines of ancient glaciers, apparently just as they were left by the ice? There are, it is true, a few considerations that go to diminish though not to remove the difficulty. The amount of denudation is now abnormally large, because the large quantities of glacial drift left over the surface of the country, supply much of the sediment carried down by the streams of Alpine countries. Many glacial markings were at first covered up and preserved by drift or alluvium, and have been since exposed by denudation : those earliest exposed are obliterated, but new surfaces are being continually uncovered. The amount of denudation of a solid rocksurface may not be a tenth part of that which now obtains in glaciated districts; a fact which can only be ascertained by determining the amount of sediment brought down by streams the basins of which are free from drift or gravel, and consist almost wholly of compact rock surfaces. We still have to deal with the difficulty of the moraines, whose form and aspect are often so fresh that we can hardly believe them to have been much changed since the ice left them, although it is impossible to understand how they have escaped the denudation which has lowered the whole surface of the country eighty, or even a much smaller number of feet.

It is true Mr. Geikie, in his paper on Modern Denudation,* suggests that all the effects of ice-action, now visible, are merely the few examples which have been preserved owing to a concurrence of favourable conditions, while a much larger number have been destroyed; and I learn from him that there are in Scotland moraines in all stages of decay. If this be the true explanation of the difficulty, it follows that denudation must be extremely unequal, and that if one valley or hill-side has remained unaltered during 80,000 years, another must have been denuded to double the average amount.

Having thus shown the difficulty there is in accepting even the shorter period of 80,000 years for the date of the end of the glacial epoch in Europe, let us see what other modes of measurement are available. In Sir Charles Lyell's "Antiquity of Man," 2nd ed., p. 28, we have three different calculations of the age of the bronze and stone periods in Switzerland, which would place the latter at about from 5,000 to 7,000 years ago. At page 32I of the same work, we have an estimate of the age of the upper delta of the Tinière by M. Morlot. The Iower delta (by the presence of Roman remains in one of the upper strata) is calculated with tolerable certainty to be Io,000 years old, while the upper delta, $150 \mathrm{ft}$. above the lake, is ten 'times as large as the lower one, and is therefore supposed to be 100,000 years old. From its fossil remains it is believed to be post-glacial; but it is evident that, during the

* Transactions of the Geological Society of Glasgow, vol, iii. p. I53. melting of the ice, the torrent might have been more powerful, and have accumulated a delta much more rapidly than now. The peat mosses of Denmark, indicating that the present beech-tree vegetation of that country, which was also characteristic of it in the Roman period, was in the Bronze age replaced by oaks, and in the still earlier Stone age by fir-trees, imply a very long lapse of time; yet this only takes us back to the Neolithic age, when all the shells and all the mammalia were of existing species. The 8,000 or 10,000 years of the Swiss Stone age may, however, have sufficed for this change. There seems to be no doubt, that the time which elapsed from the close of the glacial epoch (when man used the rudest flint weapons, and was coeval with many extinct animals, when, moreover, the climate and physical features of the country were considerably different from what they are now) up to the Neolithic age, was much greater than from the latter date to the present day, but how much greater it is impossible to determine. The position of many of the tool-bearing gravels shows that rivers then flowed at much higher levels, but from the known rate of denudation, a valley might be deepened even $500 \mathrm{r}^{\circ} \mathrm{roO} \mathrm{ft}$. in as little as 50,000 years, since it is in valleys that the effects of denudation would be greatest; and the extinction of the various animals might certainly take place in an equal time under such conditions as are not unlikely to have occurred at a period of great climatic change.

It does not appear, therefore, that any of the estimates of time founded on an actual basis of observed change in a known period, require us to assume more than 80,000 years since the close of the glacial epoch, while the measurement of the existing rate of denudation renders it almost certain that it was less rather than more. We may fairly assume, that even if a large excentricity has been an essential condition of a glacial epoch, the ice would maintain itself into a period of less excentricity than would be required to bring one on. Now 74,000 years ago the excentricity was about double what it is now, and the winter of the northern hemisphere then occurred in aphetion, so that the glacial epoch would at that time probably have been in full force, and we may assume that it might continue 3,000 or 4,000 years longer. But when we come to 65,000 years back; we find the excentricity scarcely more than it is at present, and winter nearly in perihelion; so that we must conclude, if excentricity has anything to do with it, that the last glacial period came to an end not less than 70,000 years ago.

Now it is most important to observe that, for the last 60,000 years, the excentricity has been very small-for three-fourths of the time less than it is now. During this time the opposite phases of precession, each lasting I0,500 years, will have produced scarcely any effect on climate, which in every part of the earth will have been nearly uniform for that long period. But this is quite an exceptional state of things; for the curve of excentricity shows us that, during almost the whole of the last three million years, the excentricity has been high-almost always twice, and sometimes three and four times as much as it is now. If, therefore, Mr. Croll's theory be correct, there will have been a change each 10,500 years during this vast period (in all the extratropical regions at least) from a very cold to a very mild 
climate. This will necessarily have caused much migration both of plants and animals, which would inevitably result in much extinction and comparatively rapid modification. Allied races would be continually brought into competition, altered physical conditions would induce variation, and thus we should have all the elements for natural selection and the struggle for life, to work upon and develop new races. High excentricity would therefore lead to a rapid change of species, low excentricity to a persistence of the same forms; and, as we are now, and have been for 60,000 years, in a period of low excentricity, the rate of change of species during that time may be no measure of the rate that has generally obtained in past geological epochs. Thus we should have explained the extraordinary persistence of organic forms during the historical period as well as during the preceding Neolithic age, although slight changes of climate and of physical geography have undoubtedly taken place; and it would prove to be not so much the usually slow rate of organic change, as the fact of our living in the midst of an excep. tionally uniform climatic epoch, that has hitherto preyented us from obtaining a measure of the average duration of species.

These considerations have an important bearing on our estimate of the duration of the glacial epoch itself, and on our calculation of geological time from the change of species since its commencement. If it terminated 70,000 years ago, and if each 10,500 years before that date, there was alternately a warm period and a glacial epoch, there would necessarily occur a series of northern and southern migrations of animals and plants, and thus deposits formed at times not geologically remote, might contain very distinct groups of animals. These might even meet and be confounded in the same strata, and thus lead to that extraordinary mixture of northern and southern forms which occurs in some of the more recent formations, like the hippopotamus and mammoth in the Norfolk crag and the lower brick-earths.

Geologists seem hardly to have attached sufficient importance to the great gap that intervenes between the Palæolithic and Pre-historic ages. Mr. Boyd Dawkins has shown, from a careful study of their mammalian remains, that the whole of the post-glacial river deposits and cave-beds of this country (I 48 in number) are of the same age, being characterised by about twenty species of extinct or arctic mammalia, and this was the age of Palæolithic man. In the Pre-historic or Neolithic age all these have disappeared, while the sheep, goat, dog, and Bos longifrons are first met with. Now, on the theory that this Palæolithic age was entirely post-glacial, and that the climate and physical geography of Britain have been since slowly approaching their present condition, how is this great gap to be accounted for? The large number of places where remains have been found, shows that the conditions requisite for preserving them very frequently occurred, and there must therefore have been some special cause which has prevented any record being left of the long period during which they were becoming extinct. Mr. J. Scott Moore* maintains that they were all preglacial, and that the gap was the glacial epoch itself. He adduces in corroboration the striking fact that none of the supposed post-glacial gravels ever rest on the boulder

* Pre-glacial Man and Geological Chronology, Dublin, I868. clay, but always on an older rock, which could hardly have been the case in every instance were they all postglacial. Again, Mr. Boyd Dawkins tells us that the identity of such a large proportion of the species of preglacial and post-glacial mammals "forbids the idea of the existence of any gap or lacuna which would warrant the classification of the one as tertiary and the other as quaternary." But if we admit the occurrence, during the last glacial epoch, not only of one or two, but of a series of alternate cold and warm periods, we may make the Palæolithic age inter-glacial, and suppose it to have occupied several of these alternations of climate. If we further place the last submergence which separated Britain from the Continent, during one of the later phases of extreme cold, when most of the extinct mammalia, as well as man, had migrated southwards, we shall sufficiently account for the great gap that intervenes between the Palæolithic and Pre-historic ages.

In the "Principles of Geology," Ioth ed., vol. i. p. 300, Sir C. Lyell has given an estimate of the duration of geological epochs, from the proportionate change in the species of marine mollusca, taking as a basis a million years since the beginning of the glacial epoch. Of the marine shells then living, six per cent. have become extinct, while at the close of the glacial epoch they were all of existing species, but this does not necessarily imply that the former are many times older than the latter. The glacial period itself may have been the cause of their extinction independently of mere time ; so that the Bridlington beds, where the above-mentioned proportion of extinct species occurs, need not on this account be more than twice as old as those glacial or post-glacial drifts which contain only living species, or, according to our previous estimate, about 140,000 years. The Norfolk crag, which contains eleven per cent. of extinct shells, may be from 40,000 to 60,000 years older; this will allow for two or three alternations of warm and cold periods, which, at a time of such high excentricity, must have been strongly contrasted, and have led to a correspondingly rapid change of species. From these considerations it becomes evident that the time, measured by the occurrence of five per cent. of extinct species of marine shells, is not necessarily the whole number of years which has elapsed since they existed, but only that number minus the last 60,000 years of uniform climate and specific immobility; and we may be even too lavish of time if we allow so much as 100,000 years for this amount of change under the influence of those repeated alternations of climate which have characterised the last three million years and which have probably more or less characterised all past geological time. If now we take this number as our datum instead of a million years, all Sir Charles Lyell's figures will be reduced to a tenth, and will stand thus : the time elapsed since the beginning of the--

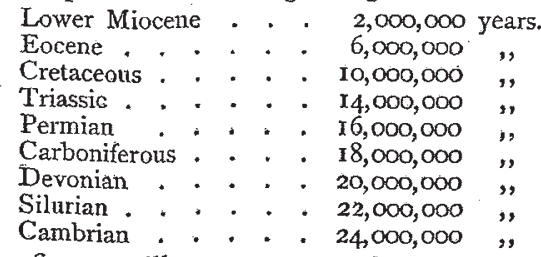

These figures will seem very small to some geologists who have been accustomed to speak of "millions". as 
small matters; but I hope I have shown that, so far as we have any means at present of measuring geological time, they may be amply sufficient. Taking Sir William Thomson's allowance of a hundred million years for the time during which the earth can have been fit for life, it yet allows Mr. Darwin, for the process of development from the primordial germ, three times as many years anterior to the Cambrian epoch as have elapsed since that date, an amount of time which, I believe, will fully satisfy him, by whatever scale we may measure it.

The evidence of the rapidity of denudation would indeed tend to the still further shortening of the estimate here given; and it is not impossible that a concurrence of geographical conditions might have brought down the glacial epoch into a period when the excentricity was no greater, or even less, than it is now. This, however, is hardly probable, and I am inclined to think that the considerations already alluded to will, to a considerable extent, explain how it is that so many signs of glacial action still remain, in spite of such denudation. The only argument I consider new in this paper, is that derived from the uniformity of climate during the last 60,000 years, and the alternations of heat and cold for a long time previously, leading to a slower change of species since the glacial epoch than at any former period, thus allowing us to suppose change of form in the organic world to go on more rapidly than we had before thought possible. If this be a sound deduction, it will, I believe, more than anything else, enable us to bring the period required for the development of the whole organic world within that which modern natural philosophy assigns as the age of the habitable earth.

Much of the force of my argument appears to depend upon the accuracy of Mr. Croll's view, that, during a time of great excentricity, there will be in each hemisphere alternately a glacial epoch for about 10,500 years, and a perpetual spring or summer for about an equal period. But Sir Charles Lyell argues, with great force, for the opposite view, that the cold of one period would be continued through the other, and that during the whole continuance of a phase of high excentricity both hemispheres would be in a state of glaciation. Supposing this view to be the true one, it will not very materially affect my argument, for the diagram shows many comparatively rapid alternations from a very high to a very low excentricity; which would also be from a glacial to a temperate climate and would certainly tend to comparative rapidity of specific change; while in each 10,500 years there would, no doubt, be some retreat and advance of the snow line, followed by a less amount of migration, competition, and variation. During the last 60,000 years, on the other hand, the change of excentricity has been hardly perceptible, and the change of organic forms may be supposed to have been far below the average.

ALFRED R. WALLACE

FRESHWATER CRUSTACEA OF NORWAY

Histoire Naturelle des Crustacés d'eau douce de Norvige; by George Ossian Sars. Part I, Malaçostraca. With Io plates. (Christiania, I867.)

SOME few years ago, much interest was excited amongst naturalists by the announcement of the occurrence, in the great Swedish lakes Venner and Vetter, of certain
Crustacea, heretofore known only as marine species inhabiting the Arctic and Baltic Seas. The author of this discovery was Professor Lovèn; and the explanation of it appeared to be, that the gradual elevation of the Scandinavian peninsula had cut off these originally marine creatures from their natural habitat, and that they had been able to accommodate themselves successfully to altered conditions of life.

In the volume now under notice, we have an elaborate -we may say almost an exhaustive-contribution to the natural history of these and other fresh-water crustacea of Norway. The species here treated are Mysis oculata, var. relicta; Gammaris neglectus; Pallasia cancelloides, var. quadrispinosa; Gammaracanthus loricatus, var. lacustris; Pontoporeia affinis; and Asellus aquaticus. One notices with surprise the absence of the most abundant freshwater Amphipod of our own country, Gammarks pulex, and its replacement by the very closely allied $G$. neglectus. The well-shrimps (Niphargus) seem also to be unnoticed as yet in Norway; neither do we find any mention of another group, inhabiting chiefly brackish water, but in some districts of England reaching into situations which, though affected more or less by tides, are yet of quite fresh-water character; e.g. Palcmon varians and Mysis vulgaris.

The anatomy and physiology of all these animals, and their points of variation from the typical marine forms, are most carefully and elaborately worked out. The following interesting remarks occur respecting Pontoporeza affinis. The males of this species are numerous, having their. antennæe either imperfectly developed or presenting a very peculiar form, except in some individuals, where, towards the end of autumn, the antennæ take on their fully developed form ; in both cases, the animals being perfectly fertile. This phenomenon is analogous to some already observed in the Cumacea and Tanaidæ. The great likeness between this and the Greenland species, $P$. femorata, led the author at one time to consider the two as presenting only varietal differences, the Norwegian species exhibiting a permanent arrest of development such as he shows to be the case with the variety relicta of Mysis oculata. This supposition, however, he was compelled to dismiss; one important fact tending to a contrary opinion being that the secondary appendage of the superior antenna contains in $P$. affinis a larger number of joints than in $P$. femorata. We would commend the dredging of our deeper lakes to the attention of English naturalists. Nothing in that direction has, so far as we know, been done in this country; and it is worthy of remark, that only in the very greatest depths of the Scandinavian lakes were the abnormal species found. That this field is not unlikely to prove a productive one near our own doors we fully believe, inas. much as we have ourselves found, and elsewhere published, some interesting instances of the occurrence of truly marine microscopic crustacea in fresh water in the west of Ireland.

It should be added, that the plates illustrating M. Sars' work are admirable specimens of the engraver's art, and leave nothing to be desired as to copiousness and accuracy. The work is altogether well produced ; the expenses, which we fear are scarcely likely to be repaid, having been generously borne by the publisher, $M$. le Réviseur d'Etat Johnsen. 